\title{
Circular RNAs in cancer: new insights into functions and implications in ovarian cancer
}

\author{
Zahra Shabaninejad ${ }^{1,2+}$, Asma Vafadar ${ }^{3 \dagger}$, Ahmad Movahedpour ${ }^{3,4}$, Younes Ghasemi ${ }^{2,3,5}$, Afshin Namdar ${ }^{6}$, \\ Hadis Fathizadeh", Mohammad Hossein Pourhanifeh ${ }^{8}$, Amir Savardashtaki $^{2,3^{*}}$ and Hamed Mirzaei ${ }^{8^{*}}$
}

\begin{abstract}
Circular RNAs (circRNAs) are a class of long non-coding RNAs (IncRNAs) which have a circular and closed loop structure. They are ubiquitous, stable, conserved and diverse RNA molecules with a range of activities such as translation and splicing regulation, which are able to interacting with RNA-binding proteins and specially miRNA sponge. The expression patterns of the circRNAs exhibited tissue specificity and also, step and stage specificity. Accumulating evidences approved the critical role of circular RNAs in many cancers such as ovarian cancer. Given that these molecules exert their effects through multiple cellular and molecular mechanisms (i.e., angiogenesis, apoptosis, growth, and metastasis) which are involved in cancer pathogenesis, circular RNAs, in particular, act by controlling cell proliferation in ovarian cancer, so that, it has been shown that the deregulation of these molecules is associated with initiation and progression of ovarian cancer. Therefore, they are attractive molecules which have introduced them as cancer biomarkers. Moreover, they could be used as new therapeutic candidates for developing novel treatment strategies. Here, for first time, we have provided a comprehensive review on the recent knowledge of circular RNAs and their pathological roles in the ovarian cancer.
\end{abstract}

Keywords: Circular RNA, MicroRNA, Ovarian cancer

\section{Introduction}

The majority portion of genome (approximately 98\%) is assigned to non-coding RNAs (ncRNAs) rather than protein coding mRNAs [1]. They are categorized into two main group: (1) housekeeper ncRNAs, which are consist of tRNAs, rRNAs, snoRNAs and snRNAs; (2) regulatory ncRNAs. Based on the nucleotide fragment length, the regulatory ncRNAs can be classified into $<200$ nucleotides in transcript length, some of which are microRNAs (miRNAs) and siRNAs, and the long non coding RNAs (lncRNAs) which possess transcripts with more than 200 nucleotides in length $[2,3]$.

\footnotetext{
*Correspondence: Dashtaki63@gmail.com; h.mirzaei2002@gmail.com; Mirzaei-h@kaums.ac.ir

†Zahra Shabaninejad and Asma Vafadar contributed equally to this work. ${ }^{2}$ Pharmaceutical Sciences Research Center, Shiraz University of Medical Sciences, Shiraz, Iran

${ }^{8}$ Research Center for Biochemistry and Nutrition in Metabolic Diseases, Institute for Basic Sciences, Kashan University of Medical Sciences, Kashan, Iran

Full list of author information is available at the end of the article
}

Circular RNAs (circRNAs) group is a member of lncRNAs with a large variation in length ranged from hundreds to thousands nucleotides [4]. During the pre-mRNA splicing, the $5^{\prime}$ end of upstream exon and the $3^{\prime}$ end of a downstream exon or the ends of an individual exon could join together to generate a circRNAs. The Circular essence of circRNAs make them more stable against RNase in comparison with linear RNA forms [5]. While majority of circRNAs are originated from coding pre-mRNA, but they are classified as lncRNAs. The circRNAs was firstly discovered in 1979 [6], but the technical limitation hindered the wide identifications and investigations. Until last two decade, emerging rapid advanced in molecular techniques like next generation sequencing, the number of identified circRNAs and researches on their function $[7,8]$.

Like other lncRNAs, circRNAs could be implicated in RNA or protein sponging to modulate gene expression. The most well-known mechanisms is in miRNA regulation by acting as competing endogenous miRNA sponge elements; in this way they post-transcriptionally provided mRNA escape miRNA repression $[9,10]$. Besides, 
they are involved in cell cycle and other physiological cell processes by making complexes with proteins [11]. In recent years, they are attracting considerable research attribute to their roles in initiation and progression of human malignancies, especially cancers.

Ovarian cancer is one of the most common gynecologic disease worldwide. In 2018, more than 295,000 new cases were diagnosed and approximately 184,000 deaths were reported worldwide [12]. Despite develops in chemotherapy and surgical treatment, the survival rate is not favorable, because of poor prognosis and cancer recurrence [13]. Without doubt, clearing the circRNAs function and roles will improve knowledge of ovarian cancer and provide new chances and opportunities to develop more effective treatment or diagnostic approaches. Herein, we reviewed properties and function of circRNAs in cancers. We also highlight the circRNAs dysregulation and functions in the regulation of ovarian cancers.

\section{CircRNA biogenesis}

In eukaryotic genes, non-coding introns that are between exons are removed after transcription by alternative splicing of pre-mRNA transcript. (in alternative splicing process of eukaryotic pre-mRNA, the introns that are non-coding region located between exons are removed after transcription.) [14]. After that, exons are reattached to each other and the spliced out introns can be formed linear or lariat molecules. Many evidence have demonstrated that circular RNAs are originated during splicing pre-mRNAs. like mRNAs, circRNAs are transcribed by RNA polymerase II (Pol II) but they have not terminal structure such as 3' poly-A tail and $5^{\prime}$ Cap that exist in the fate of RNA transcripts [4]. The lack of free end in circRNAs lead to be resistant toward endonuclease and subsequently, are more stable than their linear counterpart.

Based on sequences and genomic origins, circRNAs are divided into three classes: intronic, exon-intron and exonic, which is the most prevalent form of circRNAs (Fig. 1) [15]. Exonic circRNAs are formed during backsplicing or Exon skipping and are usually catalyzed by the spliceosomal machinery [16]. In back-splicing, which also called circle splicing or head-to-tail splicing, the segments of spliceosome lead to attach the downstream splice donor ( $5^{\prime}$ end of the intron) to an upstream splice acceptor (3'end of the intron) and circular inverting

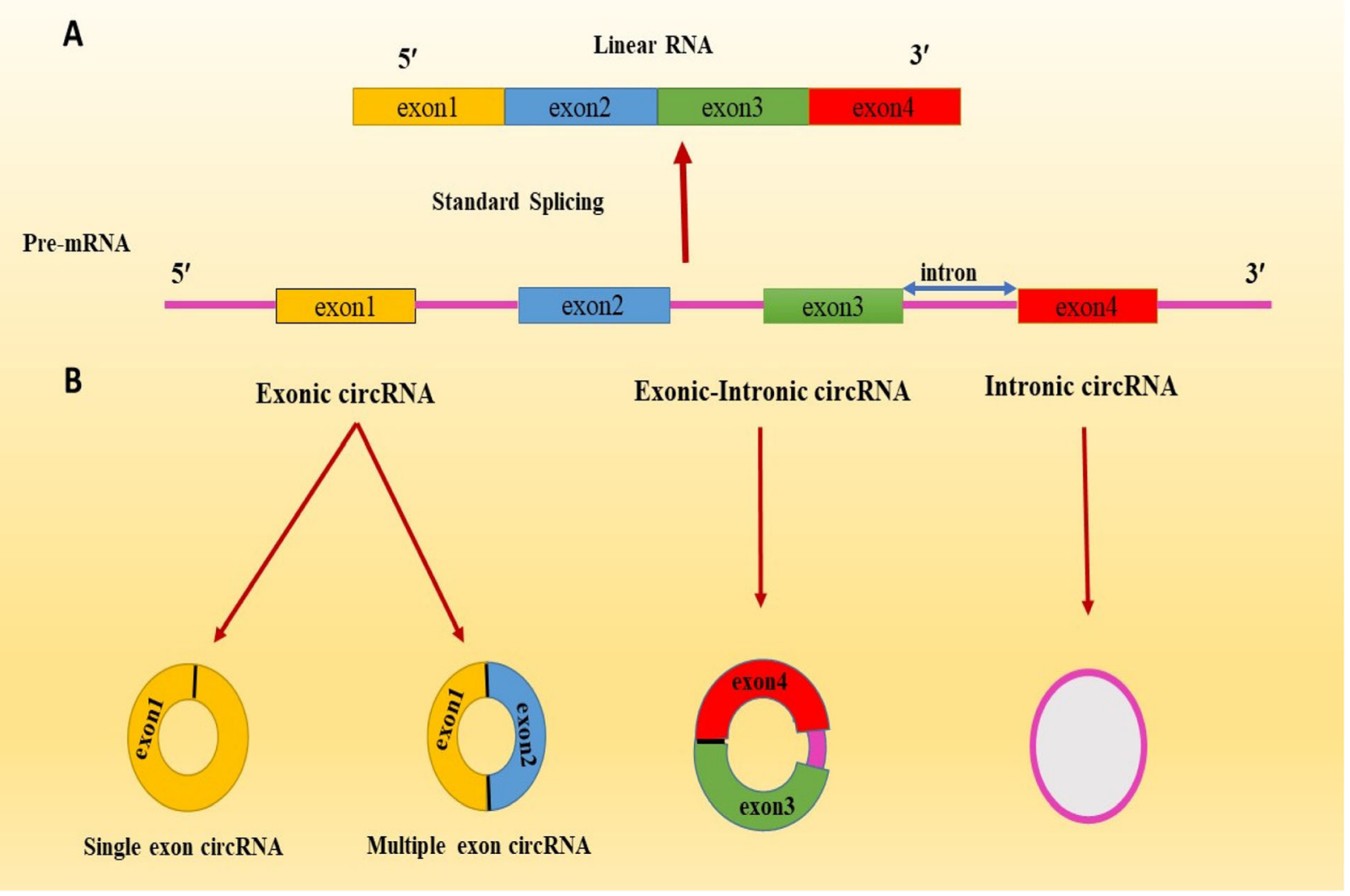

Fig. 1 The kind of biogenesis of circRNAs: (a) Standard splicing (conventional linear splicing); (b) circRNAs is generated by a process called, Backsplicing: this splicing lead to creating 1) exonic circRNA that can make two forms including single exon circRNA and multiple exon circRNA, 2) Exonic-Intronic circRNA and 3) Intronic circRNA 
RNA are produced by covalently linked ends. In multiple exons, a downstream end of exon splices to the initiation site of an upstream exon. It may also happen with single exon; in this case, the $3^{\prime}$ end of one exon binds to the $5^{\prime}$ end site $[17,18]$.

Exon skipping is the other model of splicing for producing of exonic circRNAs. In this process, when one or maybe more of the exons skipped, the introns with a loop structure, known as lariat (which resembles lasso), can formed exoncontaining lariat during internal splicing [19-21].

Generally, in eukaryotic genes, introns undergoing standard splicing is separated and degraded by enzymes. However, some of the introns have conservative sequences at both ends of them. These motifs are GU-rich element (7-nucleotide) located at the near $5^{\prime}$ splice site and the C-rich element (11-nucleotide) at $3^{\prime}$-branch site. Due to preserve motifs, The lariat introns escape of debranching enzymes, consequently, RNAs can be circularized and circular intronic RNAs (ciRNAs) are produced $[18,22]$. A feature of the intronic circRNAs that distinguishes them from exonic circRNAs is single unique $2^{\prime}-$ $5^{\prime}$ linkage, while in exonic circRNAs the phospholipid linkage is $3^{\prime}-5^{\prime}$. CircRNAs are settled in the nucleus and have a role in the regulation of parent genes [23].

Finally, exon-intron circular RNAs (EIciRNAs) can be produced from circularized exons with intron preserved between exons (Fig. 1). According further studies, it is confirmed that circRNAs and EIciRNAs are involved in Pol II transcription and both of them play role in regulation of parental gene expression. Like ciRNAs, EIciRNAs are located in nucleus [17, 24].

Recently, it is shown that some classes of the enzyme are effective in circRNAs biogenesis. RNA binding proteins (RBPs) is a group of enzymes that have a role in the generation of circRNAs in some situations and is demonstrated to act as a regulator in activation or repression circRNAs. Actually, it is proven that they play a crucial role in the control of RNA such as splicing [25]. Ashwal-Fluss et al. are exposed in their research that RBPs can monitor muscle-blind protein (MBL) levels in the fly brain [26]. In this process, when MBL level is too high, RBPs attach to pre-mRNAs and prevent to convert linear RNA and cause circRNAs, afterward, translation stops and MBL protein has not produced [27]. ADAR (adenosine deaminases acting on RNA) is another enzyme that involved in circRNAs biogenesis and can regulate RBPs level. Since ADAR has the function in RNA editing, is imperative for mammalian development. In kinds of research, it is expressed that ADAR causes decreasing formation of circRNAs through debilitating and editing RNA duplexes [7, 28].

\section{Circular RNAs and their roles in cancer pathogenesis}

Cancer is one of very important health problems $[29,30]$. It has been showed that a variety of internal (genetics and epigenetic factors) and external factors involved in cancer pathogenesis [29, 31]. Among epigenetic factors, noncoding RNAs have critical roles in the pathogenesis of many diseases such as cancer, cardiovascular diseases, and diabetes [32-35]. Considering the many challenges associated the effects of non-coding RNAs such as lncRNAs and miRNAs and their role in cancer, nowadays a new category of these non-coding RNAs, called circRNAs, have attracted considerable attention. Many evidence in recent years have confirmed that circRNAs play an important role in the onset and progression of various cancers including gastric cancer, esophageal cancer, ovarian cancer, bladder cancer, renal carcinoma, oral carcinoma, lung cancer, and hepatic carcinoma (Table 1) [42, 63-66]. According to development of techniques that were able to discover function of circRNAs, it is proven that they can affect on several pathways and aberrant expression of them causes various disease including cancer. Recently, it is demonstrated that circRNAs in numerous cancers changes expression level or even can interact with microRNAs and act as sponge miRNAs.

During a study, the expression of circ-104,916 was investigated in gastric cancer (GC) by microarray. In this inquiry, circ-104,916 was downregulated in tissue GC compare with normal tissue. After that, they performed quantitative realtime PCR (in 70 pairs of human GC specimens) to confirm the results of the microarray and figured out that the results were matched. They also showed that the overexpression of circ-104,916 via pcDNA-circ-104,916 in two GC cell line (BGC823, MGC803) lead to significantly suppressed proliferation, invasion, and migration via changing the epithelialmesenchymal transition (EMT) manner. According to the results, they claim that circ-104,916 would be appropriate biomarker for GC [36]. Recently, a novel circRNAs named Cdr1, antisense to the cerebellar degeneration-related protein 1 transcript, has been discovered. This circRNAs also called ciRS-7 which was because of the appearance as a powerful sponge for miR-7 [67, 68]. Since the result of qRT-PCR in a research demonstrated that ciRS-7 was overexpressed in GC samples compared with control tissues, it was suggested that this circRNAs could serve as a potential biomarker in GC. On the other hand, in this study the correlation between miR-7 and ciRS-7 was checked out. It was observed that the expression level of miR-7 was reduced in GC cell lines (MGC-803, HGC-27, [69]). MiR-7 is known as a tumor suppressor and can induce apoptosis in GC cell lines via modulation of the PTEN/PI3K/AKT pathway [70]. It is worth noting that overexpression of ciRS-7 has not straight effect on GC cell migration and proliferation but since they can act miR-7 sponge, lead to intensifying PTEN/PI3K/AKT pathway through repression of miR-7 [69].

The bladder cancer-related circular RNA-2 (BCRC-2), also known as circHIPK3, expression level was explored 
Table 1 Selected circular RNAs in different cancers

\begin{tabular}{|c|c|c|c|c|c|c|c|}
\hline Cancer & Circular RNA & $\begin{array}{l}\text { Regulation of } \\
\text { the expression } \\
\text { in cancer }\end{array}$ & Genetic target (s) & Effect $(s)$ & $\begin{array}{l}\text { Model } \\
\text { used }\end{array}$ & $\begin{array}{l}\text { Sample } \\
\text { type }\end{array}$ & Reference \\
\hline \multirow[t]{3}{*}{$\overline{G C}$} & CiRS-7 & Up & miR-7 & Increase the overall survival & In vitro & $\begin{array}{l}\text { Tissue, } \\
\text { cell line }\end{array}$ & \\
\hline & Circ_104,916 & Down & Unknown & Promote TNM and lymph node metastasis & In vitro & $\begin{array}{l}\text { Tissue, } \\
\text { cell line }\end{array}$ & [36] \\
\hline & Circ_0000181 & Down & Unknown & Lymphatic metastasis and distal metastasis & In vitro & $\begin{array}{l}\text { Tissues, } \\
\text { plasma }\end{array}$ & [37] \\
\hline \multirow[t]{3}{*}{ BLC } & CircHIPK3 & Down & miR-558 & Promote Vascular invasion and lymph node metastasis & $\begin{array}{l}\text { In vitro, } \\
\text { In vivo }\end{array}$ & $\begin{array}{l}\text { Tissue, } \\
\text { Cell line } \\
\text { mice }\end{array}$ & [38] \\
\hline & CircTCF25 & Up & $\begin{array}{l}\text { miR-103a } \\
\text { miR-107 } \\
\text { CDK6 }\end{array}$ & $\begin{array}{l}\text { Promote cell proliferation, } \\
\text { Migration }\end{array}$ & In vitro & $\begin{array}{l}\text { Tissue, } \\
\text { Cell line }\end{array}$ & [39] \\
\hline & CircRNA BCRC4 & Down & miR-101 & Association with cell apoptosis & In vitro & $\begin{array}{l}\text { Tissue, } \\
\text { Cell line }\end{array}$ & [40] \\
\hline \multirow[t]{3}{*}{ ESCC } & Circ-ITCH & Down & $\begin{array}{l}\text { miR-7 miR-17 } \\
\text { miR-214 }\end{array}$ & Inhibit the Wnt/ß-catenin pathway & $\begin{array}{l}\text { In vitro, } \\
\text { In vivo }\end{array}$ & $\begin{array}{l}\text { Tissue, } \\
\text { Cell line }\end{array}$ & [41] \\
\hline & hsa_circ_0067934 & Up & Unknown & Promote the proliferation and migration & In vitro & $\begin{array}{l}\text { Tissue, } \\
\text { cell line }\end{array}$ & [42] \\
\hline & circ-DLG 1 & Up & $\begin{array}{l}\operatorname{miR}-515 \\
\text { miR-942 } \\
\text { miR-589 } \\
\text { miR-136 }\end{array}$ & Promote the esophageal cell proliferation ability & In vitro & $\begin{array}{l}\text { Tissue, } \\
\text { cell line, } \\
\text { Plasma }\end{array}$ & [43] \\
\hline \multirow[t]{3}{*}{ BC } & hsa_circ_0001982 & Up & miR-143 & $\begin{array}{l}\text { Promote the proliferation and invasion and suppress } \\
\text { apoptosis }\end{array}$ & In vitro & $\begin{array}{l}\text { Cell line, } \\
\text { Tissue }\end{array}$ & [44] \\
\hline & CircMYO9B & Up & miR-4316 & $\begin{array}{l}\text { Promote the } \mathrm{BC} \text { cell proliferation, migration and } \\
\text { invasion, upregulation of FOXP4 }\end{array}$ & $\begin{array}{l}\text { In vitro, } \\
\text { In vivo }\end{array}$ & $\begin{array}{l}\text { Tissue, } \\
\text { Cell line }\end{array}$ & [45] \\
\hline & hsa_circ_0007534 & Up & miR-593 & $\begin{array}{l}\text { Promote the BC cell proliferation, colony formation, } \\
\text { and invasion, upregulation of Mucin } 19 \text { (MUC19) }\end{array}$ & In vitro & $\begin{array}{l}\text { Tissue, } \\
\text { Cell line }\end{array}$ & [46] \\
\hline \multirow[t]{3}{*}{ CRC } & CirclTGA7 & Down & miR-370-3p & $\begin{array}{l}\text { Promote the proliferation and metastasis in CRC cells } \\
\text { via Ras pathway }\end{array}$ & $\begin{array}{l}\text { In vitro, } \\
\text { In vivo }\end{array}$ & $\begin{array}{l}\text { Tissues, } \\
\text { cell line }\end{array}$ & [47] \\
\hline & hsa_circ_0000523 & Down & miR-31 & $\begin{array}{l}\text { Promote the proliferation and suppressed apoptosis } \\
\text { of CRC cells via indirectly regulating Wnt/ } \beta \text {-catenin } \\
\text { signaling pathway }\end{array}$ & $\begin{array}{l}\text { In vitro, } \\
\text { In vivo }\end{array}$ & $\begin{array}{l}\text { Tissues, } \\
\text { cell line }\end{array}$ & [48] \\
\hline & Circ-001569 & Up & miR-145 & $\begin{array}{l}\text { Promote the proliferation, cell growth and invasion } \\
\text { of CRC }\end{array}$ & In vitro & $\begin{array}{l}\text { Tissues, } \\
\text { cell line }\end{array}$ & \\
\hline \multirow[t]{3}{*}{$\mathrm{HCC}$} & CSMARCA5 & Down & $\begin{array}{l}\text { miR-17-3p } \\
\text { miR-181b-5p }\end{array}$ & Promote the growth and metastasis of HCC & $\begin{array}{l}\text { In vitro, } \\
\text { In vivo }\end{array}$ & $\begin{array}{l}\text { Tissues, } \\
\text { cell line }\end{array}$ & [49] \\
\hline & CircMTO1 & Down & miR-9 & $\begin{array}{l}\text { Promote the HCC progression and cell growth via } \\
\text { miR9-P21 }\end{array}$ & $\begin{array}{l}\text { In vitro, } \\
\text { In vivo }\end{array}$ & $\begin{array}{l}\text { Tissues, } \\
\text { cell line }\end{array}$ & \\
\hline & Circ_100,338 & Up & $\operatorname{miR}-141-3 p$ & $\begin{array}{l}\text { Promote the lung metastasis, vascular invasion, and } \\
\text { TNM }\end{array}$ & $\begin{array}{l}\text { In vitro, } \\
\text { In vivo }\end{array}$ & $\begin{array}{l}\text { Tissues, } \\
\text { cell line }\end{array}$ & [50] \\
\hline \multirow[t]{3}{*}{ OSCC } & CircRNA_100290 & Up & miR-29b & $\begin{array}{l}\text { Suppress G1/S arrest, induce cell proliferation and } \\
\text { upregulate the expression of CDK6 }\end{array}$ & $\begin{array}{l}\text { In vitro, } \\
\text { In vivo }\end{array}$ & $\begin{array}{l}\text { Tissues, } \\
\text { cell line }\end{array}$ & [51] \\
\hline & hsa_circ_0055538 & Down & $\begin{array}{l}\text { p53/Bax/Apaf1/ } \\
\text { caspase-3/ } \\
\text { p21/Bcl2 }\end{array}$ & $\begin{array}{l}\text { Development of OSCC via the p53/BCl-2/caspase } \\
\text { signaling pathway. }\end{array}$ & $\begin{array}{l}\text { In vitro, } \\
\text { In vivo }\end{array}$ & $\begin{array}{l}\text { Tissues, } \\
\text { Cell line }\end{array}$ & [52] \\
\hline & CircDOCK1 & Up & miR-196a-5p & $\begin{array}{l}\text { Inhibit the cell apoptosis via miR-196a-5p/BIRC3 } \\
\text { pathway }\end{array}$ & $\begin{array}{l}\text { In vitro, } \\
\text { In vivo }\end{array}$ & $\begin{array}{l}\text { Tissues, } \\
\text { Cell line }\end{array}$ & [53] \\
\hline \multirow[t]{3}{*}{ PCa } & Circ-SMARCA5 & Up & Unknown & Promote the cell cycle and inhibited cell apoptosis & In vitro & Cell line & [54] \\
\hline & Circ-102,004 & Up & $\begin{array}{l}\text { ERKJJNK } \\
\text { Hedgehog }\end{array}$ & $\begin{array}{l}\text { Promote the cell proliferation and decrease cell } \\
\text { apoptosis in PCa }\end{array}$ & $\begin{array}{l}\text { In vitro, } \\
\text { In vivo }\end{array}$ & $\begin{array}{l}\text { Tissues, } \\
\text { Cell line }\end{array}$ & [55] \\
\hline & CircMYLK & Up & MiR-29a & $\begin{array}{l}\text { Promote the PCa cell proliferation, invasion, and } \\
\text { migration }\end{array}$ & In vitro & $\begin{array}{l}\text { Tissue, } \\
\text { Cell line }\end{array}$ & [56] \\
\hline
\end{tabular}


Table 1 Selected circular RNAs in different cancers (Continued)

\begin{tabular}{|c|c|c|c|c|c|c|c|}
\hline Cancer & Circular RNA & $\begin{array}{l}\text { Regulation of } \\
\text { the expression } \\
\text { in cancer }\end{array}$ & Genetic target (s) & Effect $(s)$ & $\begin{array}{l}\text { Model } \\
\text { used }\end{array}$ & $\begin{array}{l}\text { Sample } \\
\text { type }\end{array}$ & Reference \\
\hline \multirow[t]{3}{*}{ LC } & Circ_100876 & Up & Unknown & $\begin{array}{l}\text { Promote the lymph node metastasis/TNM and overall } \\
\text { survival }\end{array}$ & In vitro & Tissues & [57] \\
\hline & CircFARSA & Up & $\begin{array}{l}\text { miR-330-5p } \\
\text { miR-326 } \\
\text { FASN }\end{array}$ & Promote the cell migration and invasion & $\begin{array}{l}\text { In vitro, } \\
\text { In silico }\end{array}$ & $\begin{array}{l}\text { Tissue, } \\
\text { Plasma }\end{array}$ & [58] \\
\hline & CircRNF13 & Down & miR-93-5p & Inhibit the cell invasion and metastasis & In vitro & $\begin{array}{l}\text { Tissues, } \\
\text { Cell line }\end{array}$ & [59] \\
\hline \multirow[t]{3}{*}{ OS } & hsa_circ_0001564 & Up & $\operatorname{miR}-29 c-3 p$ & $\begin{array}{l}\text { Promote the proliferation activity, repressed cell cycle } \\
\text { arrest in } \mathrm{G} 0 / \mathrm{G} 1 \text { phase, and suppressed apoptosis }\end{array}$ & In vitro & $\begin{array}{l}\text { Tissues, } \\
\text { Cell line }\end{array}$ & [60] \\
\hline & circ-0016347 & Up & miR-214 & Promote the proliferation, invasion and metastasis & $\begin{array}{l}\text { In vitro, } \\
\text { In vivo }\end{array}$ & $\begin{array}{l}\text { Tissues, } \\
\text { Cell line }\end{array}$ & [61] \\
\hline & circUBAP2 & Up & miR-143 & $\begin{array}{l}\text { Promote the osteosarcoma growth and inhibit the } \\
\text { apoptosis, and promote the osteosarcoma progression }\end{array}$ & $\begin{array}{l}\text { In vitro, } \\
\text { In vivo }\end{array}$ & $\begin{array}{l}\text { Tissues, } \\
\text { Cell line }\end{array}$ & [62] \\
\hline
\end{tabular}

BC Breast Cancer, BLC Bladder cancer, CRC Colorectal Cancer, GC Gastric Cancer, ESCC Esophageal squamous cell carcinoma, LC Lung Cancer, OSCC Oral squamous cell carcinoma, HCC Hepatocellular carcinoma, OS Osteosarcoma, PCa Prostate cancer, TNM tumor-node-metastasis, EMT epithelial-mesenchymal transition

in bladder tissue. On the basis of their result, it was shown that circHIPK3 was markedly decreased in bladder cancer cell lines and tissues. Actually, the circHIPK3 suppressed the expression of heparanase (HPSE) through sponging miR-558 [38]. HPSE is a vital mammalian enzyme that able to destroy heparin sulfate polymer and has the ability in both the extracellular matrix and cellsurface. This enzyme has a critical purpose in preliminaries tumorigenesis, invasion, and angiogenesis many cancers [71]. Due to circHIPK3 functions as a tumor suppressor and miR-558 sponger in bladder cancer tissue, reinforced expression of circHIPK3 could suppress lymph node metastasis, angiogenesis, and vascular invasion in bladder cancer cell line and inhibit bladder cancer metastasis and growth, in vivo [38].

In 2015, a study has surveyed the alteration in the expression level of circ-ITCH in esophageal squamous cell carcinoma (ESCC) tissues. They have manifested that circ-ITCH could act as a tumor suppressor in ESCC and an increase in circ-ITCH expression ITCH leaded to represses the Wnt/ $\beta$-catenin pathway through the destruction of phosphorylated Dvl2 via sponge of miR-7, miR-17 and miR-214. Their results also revealed an association between circRNAs, mRNAs, and protein and were proved that aberrant alteration among them may cause cancer beginning and progression. They have announced the down-regulation expression of cir-ITCH in ESCC tissue compare with matched normal tissue. Subsequently, the level of ITCH positively with circ-ITCH reduced and the expression of oncogenes including miR7, miR-17 and miR-214 overexpressed in ESCC and the Wnt/ $\beta$-catenin pathway not be repressed [41].

A significant overexpression of circMYO9B was reported in breast cancer (BC) tissue. Specific siRNA against circMYO9B caused suppression in proliferation, invasion and migration in MCF7 and MDA-231 cell lines. Likewise, the in vivo assay had shown a decrease in level circMYO9B tumor growth. They also described the mechanism of circMYO9B that sponged miR-4316 and enhanced expression of FOXP4 which act as tumor suppressors and oncogene, respectively [72, 73]. Clearly, the expression of miR-4316 was negatively related to circMYO9B and FOXP4 in BC tissues. Finally, they introduced circMYO9B as a prognostic biomarker for the $\mathrm{BC}$ patients and announced that CircMYO9B/miR-4316/ FOXP4 axis performed a crucial purpose in $\mathrm{BC}$ pathogenesis [45].

Another group of scientists had reported a novel circRNA named circITGA7 which was markedly downregulated in colorectal cancer CRC) tissue and cell lines. They also found that the linear form of ITGA7 has been downregulated in this cancer. The downregulation of circITGA7 and ITGA7 were associated with CRC progression. To the examine circITGA7 and ITGA7 roles in CRC, ectopic circITGA7 were overexpressed and observed proliferation and metastasis repression in CRC cells, in vitro and in vivo. CircITGA7 could sponge miR$370-3 p$ and indirectly leaded to an increase in neurofibromin 1 (NF1) which is its target and a negative regulator of Ras pathway. On the other hand, CircITGA7 through suppressing RREB1, a transcription factor which activate Ras pathway transcription factor, leaded to ITGA7 overexpression. RNA-Seq and KEGG pathway analysis showed that ITGA7 may be concomitant in cytokine-related signaling pathways [47].

It is well-known that the miR-17-3p and miR-181b-5p overexpression are contribute to the progression of hepatocellular carcinoma (HCC) [74, 75]. Yu et al. have shown that a circRNA named cSMARCA5, might regulate expression of miR-17-3p and miR-181b-5p oncomirs. But, 
they also have identified that cSMARCA5 is downregulated in HCC tissue and cells while mRNA and protein form of cSMARCA5 that is SMARCA5 were overexpressed. It has been noted that cSMARCA5 via sponging miR-17-3p and miR-181b-5p can promote expression of a tumor suppressor called TIMP3. Likewise, they determined that the downregulation of cSMARCA5 is an association of a tumor-promoter gene DHX9 in HCC. On the basis of results, it is concluded that cSMARCA5 may prevent the growth and metastasis of $\mathrm{HCC}$ and work as a prognostic biomarker in HCC patients [49].

One report described the expression and function of Circular SMARCA5 (circ-SMARCA5) in prostate cancer (PCa). Due to circ-SMARCA5 up-regulation in PCa tissues and cell lines, it is known as oncogenic circRNAs in this cancer. The double hydrogen testosterone (DHT), is a natural hormone and can be used as a medication, treatment resulted in circ-SMARCA5 down-regulation which can be concluded that it is an androgen-inducible circRNA. The circ-SMARCA5 silencing in DU145, a PCa originated cell line, inhibited cell cycle, cell proliferation and motivated apoptosis in PCa cells [54].

The circFARSA, derived from phenylalanyl-tRNA synthetase alpha chain (FARSA) gene, has been upregulated in non-small cell lung cancer (NSCLC) tissue compared to non-cancerous tissue. The circFARSA overexpression leaded to migration and invasion NSCLC cells. In silico analysis and HITS-CLIP experiment showed that miR-330-5p and miR-326 counterparted in the fatty acid synthesis and they were introduced as circFARSA direct targets. It is the hypothesis that circFARSA act as the sponger for miR-330-5p and miR-326 and subsequently when overexpressed lead to upregulation of FASN, a target of both miRNAs [57].

CircNOL10 can be described as a round RNA whose expression takes place in low amounts when experiencing lung cancer, although there is no clear information on the functioning mechanisms in this disease [45]. Nan and colleagues evaluated the role and molecular processes of circNOL10 in their study of lung cancer advancement in the laboratory conditions as well as in living tissues [45]. According to their findings, circNOL10 could considerably hamper progress of lung cancer, while regulation of its expression was concurrent with methylation of its parental gene named Pre-NOL10 as well as intertwining factor of epithelial splicing regulatory protein 1 or ESRP1.

CircNOL10 elevates the expression of the transcribing factor of sex comb on midleg-like 1 (SCML1) through inhibition of ubiquitination, which subsequently influences the balance of $\mathrm{HN}$ polypeptide group through SCML1. Moreover, circNOL10 can influence the performance of mitochondria by regulation of the $\mathrm{HN}$ polypeptide group along with its effects on several signaling routes, which will eventually hamper multiplication of the cell along with the development of its cycle. As a result, apoptosis is promoted in the lung cancer cells and results in the inhibition of their growth.

The present research aimed to find out how circNOL10 acts and what molecular mechanisms are involved in advancement of lung cancer in addition to indicating its engagement in the transcriptional regulation of the HN polypeptide group via SCML1. According to the findings, HN could hamper the development of lung cancer cells. The information obtained through this study may be helpful in identification of new molecular treatments for lung cancer [45].

In oral squamous cell carcinomas (OSCC), circRNA 100290 was significantly upregulated in tissue compared with adjacent non-cancerous tissue. Actually, it was represented that circRNA_100290 regulate CDK6 expression with the competing endogenous RNA (ceRNA) mechanism. CircRNA_100290 could act as spongers for miR-29 family such as miR-29a, miR-29b, and miR-29c. Among them, it was clarified that CDK6 is a direct target of miR$29 \mathrm{~b}$. On the basis of considerations, it was exposed to circRNA_100290 and CDK6 were up-regulated in OSCC. To investigate the circRNA_100290 function in OSCC cell lines, the CDK6 expression was downregulated and caused cell proliferation in vitro and in vivo with knocking down of this circRNA [51].

The last circular RNA that introduced in this part is circ_001564. The circ_001564 was highly upregulated in osteosarcoma tissue and cell lines. In order to represent the circ_001564 mechanisms, it was knocked down in osteosarcoma cell lines (HOS and MG-63). The results manifested restraining the cell proliferation, induced cell cycle arrest in G0/G1 phase and increased apoptosis in osteosarcoma cell lines. Base on bioinformatics analysis, miR-29c-3p might be bonded to circ_001564 complementary; consequently, the oncogenic effect of hsa_circ_001564 was be reversed. In addition, the circ_001564 had function as miR-29c-3p sponge that proposed competing endogenous RNAs (ceRNAs) mechanisms in osteosarcoma [60].

\section{CircRNAs in exosomes}

For the first time, Huang et al., considered the existence of circRNAs in exosomes [55]. As a result of this finding new horizons were provided to examine circRNAs. In total, locating circRNAs in the cytoplasm can be done more conveniently, while different sorts of circRNAs can be found in exosomes of various kinds of cytoplasm, which in turn indicates the potential active regulation of special circRNAs transfer to exosomes through a selection-based procedure. Nevertheless, there is no clear information available on the mechanisms through which transfer of circRNAs into exosomes takes place.

Two presumptions can be considered regarding how circRNAs act in exosomes. According to the first one, 
they facilitate cell correspondence through the existing substance in exosomes, making distal cells' material and transmission of information possible. Based on the second assumption, circRNAs in exosomes assist in elimination of circRNAs collected in cells. However, recent studies do not provide clear information on these presumptions. Lasda et al. endeavored to examine this assumption and they accordingly hypothesized that circRNAs in exosomes along with extracellular vesicles could play the role of a mechanism removing endogenous circRNAs [56].

Analysis of the corresponding number of circRNAs along with linear RNAs was performed in the present study taking extracellular vesicles (consisting of exosomes) of the Hela, $293 \mathrm{t}$, U2OS cells into account. According to the findings circRNAs outperformed the linear RNAs. Accordingly, it was stated that cells would probably have the potential to manage circRNAs by their excretion through extracellular vesicles. Since, it would be possible fot the EVs to be captured by other cells, such as macrophages, their function as message carriers could be possible in order to maintain intercellular communication. This is a new presumption which of course needs to be validated.

Enrichment of circRNAs was performed in another study in platelet due to exonuclease [58]. But the question was whether similar causes and findings could be found when linear RNA was broken down. Consequently, this potential issue was not thoroughly disapproved in the present paper. Down-regulation of circRNAs takes place in the colon of mutant KRAS, while its secretion could be accomplished in the exosomes [59].

Three types of colorectal cancer cell lines were investigated in the present research, including DLD1(wild-type along with G13D abnormal KRAS alleles), DKO-1 (just abnormal KRAS allele) as well as DKs-8 (just wild-type KRAS allele). The circRNAs of the three mentioned cell types underwent analysis through RNASeq. Considerable down-regulation of circRNAs was observed in DLD-1 as well as DKO-1 cells rather than DKs-8 cells.

Later, examination of two other colorectal cancer cell lines including HCT116 (abnormal KRAS allele) and HKe3 (the kind of wild KRAS allele) went on, with the findings obtained from sequencing confirming the fact that overall expression of circRNAs was higher in HKe3 compared with HCT116. CircRNAs associated with colorectal cancer is found in exosomes and considerable down-regulation of circFAT1 was observed contrary to up-regulation of circRTN4. However, there were no evident changes in the respective linear mRNA which was under regulating effects of these genes as it was evident in circRNAs. Moreover, it could be stated that transmission of cirRNAs into exosomes would be performed through an elective procedure [59].

\section{Circular RNAs and ovarian cancer}

Accumulating studies have confirmed interplay between circRNAs and human disorders including embryonic development, Alzheimer's disease, diabetes and also cancers [15, 76]. Ovarian cancer is one of the major prevalent and causing cancer mortality in female [77]. Dysregulation of signaling pathways and cellular mechanisms have crucial role in cancer initiation, progression and invasion $[69,78]$. Regarding regulatory roles of circRNAs and ovarian cancer impotency, the correlation and relation between them are attractive for researchers. In recent years, numerous studies focused on differentially expressed circRNAs and their function in ovarian cancers, suggesting circRNAs as potentially novel biomarkers or therapeutic agents in this disease (Table 2).

For the first time, Ahmed, et al., performed a robust circRNAs expression analysis in clinical ovarian tumors. They reported that abundant number of circRNAs differentially expressed in tumor samples. They also examined differential mRNA and circRNA expression signatures between primary and metastasis ovarian tumor. Regarding the RNA exonuclease resistance and stability of circRNAs [92], they distinguished suitably the primary tumor from metastatic lesion rather mRNAs. Interestingly, signaling pathways such as STAT, AKT, NF-kB, TGF-B, ILK and HGF and VEGF that are typically activated for linear RNA producing and angiogenesis are downregulated for circRNA in ovarian metastasis cancer [93]. Also, miR-24 and Let-7, well-known tumor suppressor miRNAs [94, 95], expressed in low level in primary tumor. The high expressed candidate circRNAs encompass several binding sites, suggesting the possible sponge roles of them for both miRNAs. Over all, the circRNAs/ miRNAs/mRNAs cross talk indicated potentially role of circRNAs as tumor activator of inhibitor [93].

The circ-CSPP1 or circ-0001806 is derived from centrosome/spindle pole-associated protein 1 (CSPP1) gene which is located in 8q13.2 region of human genome. The oncogenic function of CSPP1 have determined in luminal breast cancer and B-cell lymphoma [96, 97]. Also, the expression level of circ-CSPP1 was performed in border line, benign, ovarian tumor tissues, and non-tumor tissues. The circ-CSPP1 expressed remarkably high in borderline and tumor tissues rather benign and cancer tissues. Consistently, this circRNA expression was correlated with stage II-VI. Subsequent knocking down of circ-CSPP1 caused an arrest in cell growth, invasion and migration and inversely, the overexpression stimulated cancer properties. A negative correlation between miR-1236-3p and circCSPP1 was observed in ovarian cell lines. Dual luciferase assay revealed that circ-CSSP1 acted as miR-1236-3p decoy [84]. Reportedly, miR-1236-3p suppressed tumor development through targeting zinc finger E-box binding homobox 1 (ZEB1) in ovarian cancer [98]. Thus, circ- 


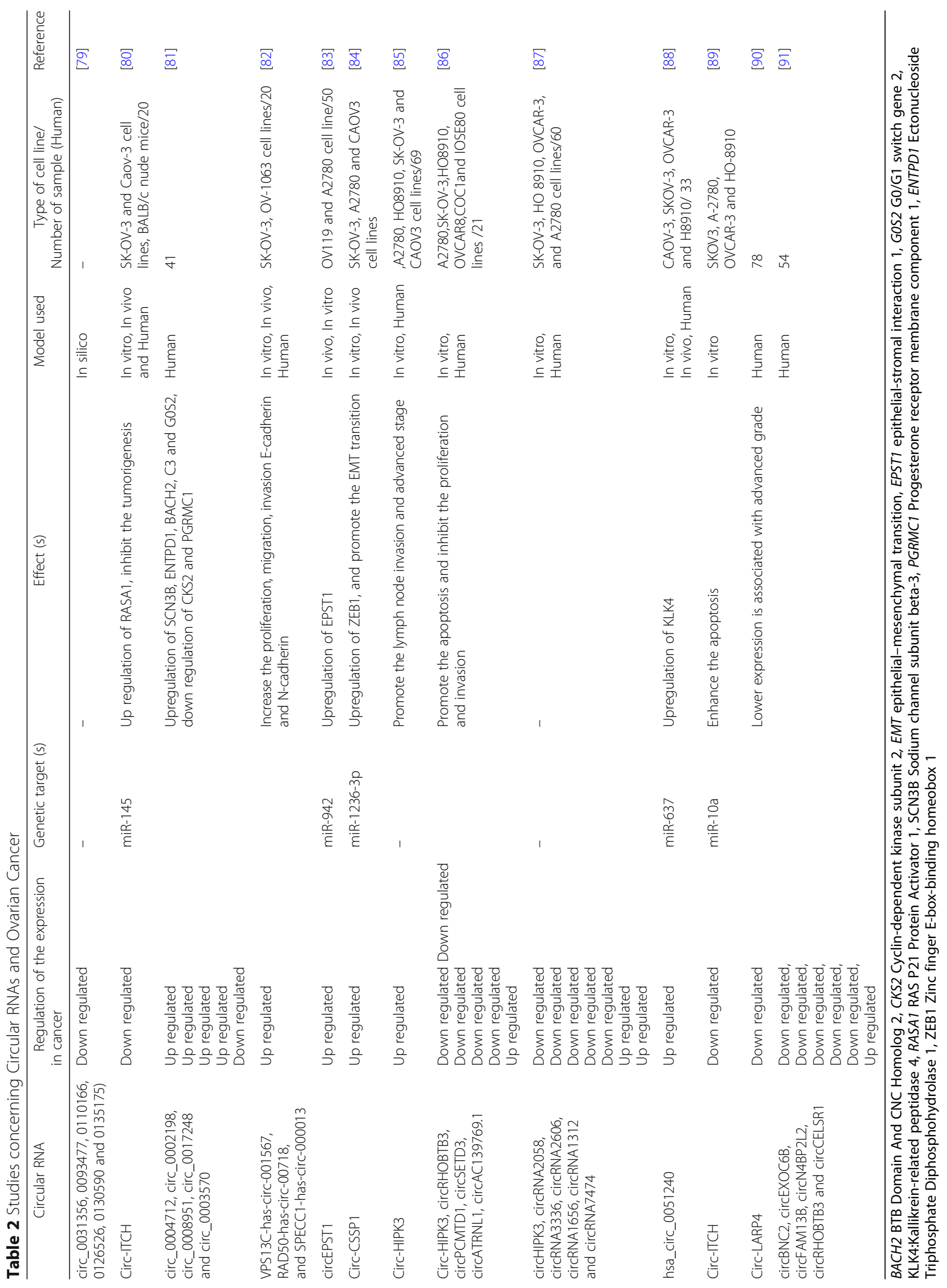


CSPP1 sponged miR-1236-3p and attenuated its silencing effect on ZEB1, consequently stimulated EMT and cancer development. Moreover, the expression of vascular endothelial growth factor A (VEGFA) and matrix metalloproteinase-2 (MMP2), which are oncogenic proteins, decreased significantly in silenced circCSPP1 cell line [84].

The overexpression of circRNA-000479, or circEPSTI1 was reported in triple-negative breast (TNBC) cancer tissues. The high level of circEPSTI1 was correlated with reduced survival in these patients. The circEPSTI1 promoted proliferation and clonal formation and suppressed apoptosis in TNBC cell lines. Moreover, xenograft and invitro experiments confirmed its role as a decoy of miR4753 and miR-6809 to modulate BCLI 1A [99]. The circEPSTI1 also played an important role in ovarian cancer regulation. Compared to adjacent non-tumor tissue, the circEPST1 was overexpressed in 50 paired ovarian cancer sample. Also, the circEPSTI1 silencing impaired cell growth, invasion but induced apoptosis. Knocking down of circEPSTI1 leaded to a decrease in ovarian tumor size and lung metastasis in mouse xenograft which indicated the circEPSTI1 role in ovarian cancer progression and metastasis invivo. Based on experimental assays, this circRNA mostly localized in cytoplasm was capable to sponge miR942, which was down regulated in ovarian cancer tissues. EPSTI1, linear form of circEPSTI1, also overexpressed in ovarian cancer tissues. Luciferase assay showed that miR942 directly targeted EPSTI1, indicating the circEPSTI1 effect on EPSTI1 [83].

The role of circHIPK3 was investigated in some human malignancies. For instance, the circHIPK3 overexpression was reported in prostate cancer tissues which was correlated with tumor stage. This circRNA relieved MCL1 expression by sponge miR-193-3p [100]. Its expression level and function was tested and the data revealed upregulation of circHIPK3 in lung cancer cells compared with lung epithelial cells. It could promote oncogenic properties by acting as a decoy for miR-124 and subsequently causing upregulation in its target including SphK1, CDK4 and STAT3 [101]. This circRNA could sponge multiple miRNAs including miR-124, miR584, miR-29a, miR-29b, miR-379 and miR-558 [38, 102].

Also, it was investigated the circHIPK3 expression correlation with clinicopathological factors in the tissues associated with ovarian cancer.

The circHIPK3 profiling revealed an increased expression in tumor samples. The over expressed cases suffered from node invasion and inappropriate prognosis [85]. Contradictory, it has been reported that circHIPK3 expressed in low level in epithelial ovarian cancer, but it was highly expressed in IOSE80 cell, a normal ovarian tissue cell line. In addition, the authors claimed that knocking down of circHIPK3 induced cell growth, migration and metastasis and repressed apoptosis of ovarian cancer cells [86]. The circ-0051240 is another circRNA that play a crucial role in ovarian cancer. The over expression of circ-0051240 in ovarian cancer tissues enhanced tumor formation, cell growth, progression and invasion, invivo and invitro. It was identified that the circ-0051240 affected via tapping miR-637 which posttransitionally inhibited Kallikrein 4 (KLK4) expression [88]. It was reported that the KLK4 overexpression was related with more aggressive and poor-prognostic ovarian cancer [103].

Emerging evidence represented the over expression and oncogenic role of miR-10a in ovarian cancer $[104,105]$. Luo and colleagues indicated a reduction in circ-ITCH expression in cancerous ovarian cell lines in comparison with non-cancerous ones and its effect on miR-10a level. The over expression of circITCH promoted apoptosis and inhibited cell proliferation in ovarian cancer cells. The miR-10a expression was adversely regulated with circ-ITCH and the miRNA overexpression compensated the circ-ITCH inhibition effects on cell growth. Interestingly, the circ-ITCH expression was independent with miR-10a expression [89]. The circ-LARP4 is another down regulated circRNA in ovarian cancer tissue. The low expression of circ-LARP4 was considerably associated with lymph node invasion and also poor prognosis. Hence, it might be used as a potentially novel biomarker for ovarian cancer detection [90].

\section{Conclusion}

Previously, circRNAs were known as errors during RNA splicing. Developing technology in recent years improved our knowledge about this class of lncRNAs. Nowadays, they are understood to be a frequently stable RNA molecule which expressed in various tissues and cells. The circRNAs represent a miRNAs decoy role to indirectly modulate their target genes. Accumulating evidences revealed the critical regulatory roles of them in tumorigenesis, with cancer-type specific distinguishable expression levels. CircRNAs biological functions, such as interactions with specific mRNA, protein and specifically miRNAs provide a regulatory network for cancer progression and invasion, so promise to providing more reliable, sensitive diagnoses and more effective cancer therapy. Based on reports, ovarian cancer is the sixth and one of the lethality cancer type in women worldwide. Without doubt, accurate knowledge about regulating molecular mechanisms, including circRNAs role provides a promising opportunity to better understanding of ovarian cancer. Subsequently novel approaches can be identified to early diagnosis, prognosis, follow up and therapeutics of ovarian cancers. 


\section{Acknowledgements}

Not applicable.

\section{Authors' contributions}

HM and AS contributed in conception, design, statistical analysis and drafting of the manuscript. ZSH, AV, AM, YGH, MHP, HF and AN contributed in data collection and manuscript drafting. All authors approved the final version for submission.

\section{Funding}

The present study was founded by a grant from the Vice Chancellor for Research, Kashan University of Medical Sciences, in Iran.

\section{Availability of data and materials}

The primary data for this study is available from the authors on direct request.

\section{Ethics approval and consent to participate}

This study was considered exempt by the KAUMS Institutional Review Board.

\section{Consent for publication}

Not applicable.

\section{Competing interests}

The authors declare that they have no competing interests.

\section{Author details}

${ }^{1}$ Department of Nanobiotechnology, School of Basic Sciences, Tarbiat Modares University, Tehran, Iran. ${ }^{2}$ Pharmaceutical Sciences Research Center, Shiraz University of Medical Sciences, Shiraz, Iran. ${ }^{3}$ Department of Medical Biotechnology, School of Advanced Medical Sciences and Technologies, Shiraz University of Medical Sciences, Shiraz, Iran. ${ }^{4}$ Student Research Committee, Shiraz University of Medical Sciences, Shiraz, Iran. ${ }^{5}$ Department of Pharmaceutical Biotechnology, School of Pharmacy and Pharmaceutical Sciences Research Center, Shiraz University of Medical Sciences, Shiraz, Iran. ${ }^{6}$ Department of Dentistry, Faculty of Medicine and Dentistry, University of Alberta, Edmonton, Canada. 'Department of Microbiology and Immunology, Faculty of Medicine, Kashan University of Medical Sciences, Kashan, Iran. ${ }^{8}$ Research Center for Biochemistry and Nutrition in Metabolic Diseases, Institute for Basic Sciences, Kashan University of Medical Sciences, Kashan, Iran.

\section{Received: 9 May 2019 Accepted: 20 August 2019}

\section{Published online: 03 September 2019}

\section{References}

1. Laurent GS, Wahlestedt C, Kapranov P. The landscape of long noncoding RNA classification. Trends Genet. 2015;31(5):239-51.

2. Hombach S, Kretz M. Non-coding RNAs: classification, biology and functioning. In: Slaby O, Calin G. (eds) Non-coding RNAs in Colorectal Cancer. Adv Exp Med Biol. Springer: Cham. 2016;937:3-17.

3. Romano G, Veneziano D, Acunzo M, Croce CM. Small non-coding RNA and cancer. Carcinogenesis. 2017;38(5):485-91.

4. Chen L-L. The biogenesis and emerging roles of circular RNAs. Nat Rev Mol Cell Biol. 2016;17(4):205.

5. Enuka Y, Lauriola M, Feldman ME, Sas-Chen A, Ulitsky I, Yarden Y. Circular RNAs are long-lived and display only minimal early alterations in response to a growth factor. Nucleic Acids Res. 2015;44(3):1370-83.

6. Hsu M-T, Coca-Prados M. Electron microscopic evidence for the circular form of RNA in the cytoplasm of eukaryotic cells. Nature. 1979;280(5720):339.

7. Rybak-Wolf A, Stottmeister C, Glažar P, Jens M, Pino N, Giusti S, Hanan M, Behm M, Bartok O, Ashwal-Fluss R. Circular RNAs in the mammalian brain are highly abundant, conserved, and dynamically expressed. Mol Cell. 2015; 58(5):870-85.

8. Salzman J, Gawad C, Wang PL, Lacayo N, Brown PO. Circular RNAs are the predominant transcript isoform from hundreds of human genes in diverse cell types. PLoS One. 2012;7(2):e30733.

9. Hansen $\mathrm{TB}$, Jensen $\mathrm{TI}$, Clausen BH, Bramsen JB, Finsen B, Damgaard CK, Kjems J. Natural RNA circles function as efficient microRNA sponges. Nature. 2013;495(7441):384.

10. Lasda E, Parker R. Circular RNAs: diversity of form and function. Rna. 2014; 20(12):1829-42.
11. Du WW, Yang W, Liu E, Yang Z, Dhaliwal P, Yang BB. Foxo3 circular RNA retards cell cycle progression via forming ternary complexes with p21 and CDK2. Nucleic Acids Res. 2016;44(6):2846-58.

12. Bray F, Ferlay J, Soerjomataram I, Siegel RL, Torre LA, Jemal A. Global cancer statistics 2018: GLOBOCAN estimates of incidence and mortality worldwide for 36 cancers in 185 countries. CA Cancer J Clin. 2018;68(6):394-424.

13. Rizzuto I, Stavraka C, Chatterjee J, Borley J, Hopkins TG, Gabra H, GhaemMaghami S, Huson L, Blagden SP. Risk of ovarian cancer relapse score: a prognostic algorithm to predict relapse following treatment for advanced ovarian cancer. Int J Gynecol Cancer. 2015;25(3):416-22.

14. He J, Xie Q, Xu H, Li J, Li Y. Circular RNAs and cancer. Cancer Lett. 2017;396: $138-44$.

15. Greene J, Baird A-M, Brady L, Lim M, Gray SG, McDermott R, Finn SP. Circular RNAs: biogenesis, function and role in human diseases. Front Mol Biosci. 2017:4:38

16. Ebbesen KK, Kjems J, Hansen TB. Circular RNAs: identification, biogenesis and function. Biochimica et Biophysica Acta (BBA)-Gene Regulatory Mechanisms. 2016;1859(1):163-8.

17. Li Z, Huang C, Bao C, Chen L, Lin M, Wang X, Zhong G, Yu B, Hu W, Dai L. Exon-intron circular RNAs regulate transcription in the nucleus. Nat Struct Mol Biol. 2015;22(3):256.

18. Vicens Q, Westhof E. Biogenesis of circular RNAs. Cell. 2014;159(1):13-4.

19. Barrett SP, Wang PL, Salzman J. Circular RNA biogenesis can proceed through an exon-containing lariat precursor. elife. 2015;4:e07540.

20. Jeck WR, Sorrentino JA, Wang K, Slevin MK, Burd CE, Liu J, Marzluff WF, Sharpless NE. Circular RNAs are abundant, conserved, and associated with ALU repeats. Rna. 2013;19(2):141-57.

21. Burd CE, Jeck WR, Liu Y, Sanoff HK, Wang Z, Sharpless NE. Expression of linear and novel circular forms of an INK4/ARF-associated non-coding RNA correlates with atherosclerosis risk. PLoS Genet. 2010;6(12):e1001233.

22. Li X, Yang L, Chen L-L. The biogenesis, functions, and challenges of circular RNAs. Mol Cell. 2018;71(3):428-42.

23. Liu L, Wang J, Khanabdali R, Kalionis B, Tai X, Xia S. Circular RNAs: isolation, characterization and their potential role in diseases. RNA Biol. 2017;14(12):1715-21.

24. Zhang Y, Zhang X-O, Chen T, Xiang J-F, Yin Q-F, Xing Y-H, Zhu S, Yang L, Chen L-L. Circular intronic long noncoding RNAs. Mol Cell. 2013;51(6):792-806.

25. Conn SJ, Pillman KA, Toubia J, Conn VM, Salmanidis M, Phillips CA, Roslan S, Schreiber AW, Gregory PA, Goodall GJ. The RNA binding protein quaking regulates formation of circRNAs. Cell. 2015;160(6):1125-34.

26. Ashwal-Fluss R, Meyer M, Pamudurti NR, Ivanov A, Bartok O, Hanan M, Evantal N, Memczak S, Rajewsky N, Kadener S. circRNA biogenesis competes with pre-mRNA splicing. Mol Cell. 2014;56(1):55-66.

27. Zang J, Lu D, Xu A. The interaction of circRNAs and RNA binding proteins: An important part of circRNA maintenance and function. J Neurosci Res. 2018. https://doi.org/10.1002/jnr.24356. [Epub ahead of print]

28. Shi L, Yan P, Liang Y, Sun Y, Shen J, Zhou S, Lin H, Liang X, Cai X. Circular RNA expression is suppressed by androgen receptor (AR)-regulated adenosine deaminase that acts on RNA (ADAR1) in human hepatocellular carcinoma. Cell Death Dis. 2017:8(11):e3171.

29. Mirzaei HR, Mirzaei H, Lee SY, Hadjati J, Till BG. Prospects for chimeric antigen receptor (CAR) gammadelta T cells: a potential game changer for adoptive T cell cancer immunotherapy. Cancer Lett. 2016;380(2):413-23.

30. Mirzaei HR, Sahebkar A, Salehi R, Nahand JS, Karimi E, Jaafari MR, Mirzaei H. Boron neutron capture therapy: moving toward targeted cancer therapy. J Cancer Res Ther. 2016:12(2):520-5.

31. Keshavarzi M, Sorayayi S, Jafar Rezaei M, Mohammadi M, Ghaderi A, Rostamzadeh A, Masoudifar A, Mirzaei H. MicroRNAs-Based Imaging Techniques in Cancer Diagnosis and Therapy. J Cell Biochem. 2017;118(12):4121-8.

32. Rabieian R, Boshtam M, Zareei M, Kouhpayeh S, Masoudifar A, Mirzaei H: Plasminogen Activator Inhibitor Type-1 as a Regulator of Fibrosis. J Cell Biochem. 2018;119(1):17-27.

33. Saeedi Borujeni MJ, Esfandiary E, Taheripak G, Codoner-Franch P, AlonsoIglesias E, Mirzaei H. Molecular aspects of diabetes mellitus: Resistin, microRNA, and exosome. J Cell Biochem. 2018;119(2):1257-72.

34. Mirzaei H, Ferns GA, Avan A, Mobarhan MG. Cytokines and MicroRNA in coronary artery disease. Adv Clin Chem. 2017:82:47-70.

35. Gholamin S, Mirzaei H. GD2-targeted immunotherapy and potential value of circulating microRNAs in neuroblastoma. J Cell Physiol. 2018;233(2):866-79.

36. Li J, Zhen L, Zhang Y, Zhao L, Liu H, Cai D, Chen H, Yu J, Qi X, Li G. Circ104916 is downregulated in gastric cancer and suppresses migration and invasion of gastric cancer cells. Onco Targets Ther. 2017;10:3521-9. 
37. Zhao Q, Chen S, Li T, Xiao B. Clinical values of circular RNA 0000181 in the screening of gastric cancer. J Clin Lab Anal. 2018:32(4):e22333.

38. Li Y, Zheng F, Xiao X, Xie F, Tao D, Huang C, Liu D, Wang M, Wang L, Zeng F. CircHIPK3 sponges miR-558 to suppress heparanase expression in bladder cancer cells. EMBO Rep. 2017;18(9):1646-59.

39. Zhong Z, Lv M, Chen J. Screening differential circular RNA expression profiles reveals the regulatory role of circTCF25-miR-103a-3p/miR-107-CDK6 pathway in bladder carcinoma. Sci Rep. 2016;6:30919.

40. Li B, Xie F, Zheng F-X, Jiang G-S, Zeng F-Q, Xiao X-Y. Overexpression of CircRNA BCRC4 regulates cell apoptosis and MicroRNA-101/EZH2 signaling in bladder cancer. Current Med Sci. 2017;37(6):886-90.

41. Li F, Zhang L, Li W, Deng J, Zheng J, An M, Lu J, Zhou Y. Circular RNA ITCH has inhibitory effect on ESCC by suppressing the Wnt/beta-catenin pathway. Oncotarget. 2015;6(8):6001-13.

42. Xia W, Qiu M, Chen R, Wang S, Leng X, Wang J, Xu Y, Hu J, Dong G, Xu L. Circular RNA has_circ_0067934 is upregulated in esophageal squamous cell carcinoma and promoted proliferation. Sci Rep. 2016;6:35576.

43. Rong J, Wang Q, Zhang Y. Circ-DLG 1 promotes the proliferation of esophageal squamous cell carcinoma [erratum]. OncoTargets Therapy. 2019;12:255.

44. Tang Y-Y, Zhao P, Zou T-N, Duan J-J, Zhi R, Yang S-Y, Yang D-C, Wang X-L. Circular RNA hsa_circ_0001982 promotes breast cancer cell carcinogenesis through decreasing miR-143. DNA Cell Biol. 2017;36(11):901-8.

45. Wang N, Gu Y, Li L, Wang F, Lv P, Xiong Y, Qiu X. Circular RNA circMYO9B facilitates breast cancer cell proliferation and invasiveness via upregulating FOXP4 expression by sponging miR-4316. Arch Biochem Biophys. 2018;653:63-70.

46. Song L, Xiao Y. Downregulation of hsa_circ_0007534 suppresses breast cancer cell proliferation and invasion by targeting miR-593/MUC19 signal pathway. Biochem Biophys Res Commun. 2018;503(4):2603-10.

47. Califf RM. Biomarker definitions and their applications. Exp Biol Med (Maywood). 2018;243(3):213-21.

48. Jin Y, Yu L, Zhang B, Liu C, Chen Y: Circular RNA hsa_circ_0000523 regulates the proliferation and apoptosis of colorectal cancer cells as miRNA sponge. Braz J Med Biol Res 2018, 51(12).

49. Yu J, Xu Q-G, Wang Z-G, Yang Y, Zhang L, Ma J-Z, Sun S-H, Yang F, Zhou WP. Circular RNA cSMARCA5 inhibits growth and metastasis in hepatocellular carcinoma. J Hepatol. 2018;68(6):1214-27.

50. Huang X-Y, Huang Z-L, Xu Y-H, Zheng Q, Chen Z, Song W, Zhou J, Tang Z$Y$, Huang $X-Y$. Comprehensive circular RNA profiling reveals the regulatory role of the circRNA-100338/miR-141-3p pathway in hepatitis B-related hepatocellular carcinoma. Sci Rep. 2017;7(1):5428.

51. Chen L, Zhang S, Wu J, Cui J, Zhong L, Zeng L, Ge S. circRNA_100290 plays a role in oral cancer by functioning as a sponge of the miR-29 family. Oncogene. 2017;36(32):4551.

52. Su W, Sun S, Wang F, Shen Y, Yang H. Circular RNA hsa_circ_0055538 regulates the malignant biological behavior of oral squamous cell carcinoma through the p53/BCl-2/caspase signaling pathway. J Transl Med. 2019;17(1):76.

53. Wang L, Wei Y, Yan Y, Wang H, Yang J, Zheng Z, Zha J, Bo P, Tang Y, Guo X. CircDOCK1 suppresses cell apoptosis via inhibition of miR-196a-5p by targeting BIRC3 in OSCC. Oncol Rep. 2018;39(3):951-66.

54. Kong Z, Wan X, Zhang Y, Zhang P, Zhang Y, Zhang X, Qi X, Wu H, Huang J, Li Y. Androgen-responsive circular RNA circSMARCA5 is up-regulated and promotes cell proliferation in prostate cancer. Biochem Biophys Res Commun. 2017:493(3):1217-23.

55. Si-Tu J, Cai Y, Feng T, Yang D, Yuan S, Yang X, He S, Li Z, Wang Y, Tang Y. Upregulated circular RNA circ-102004 that promotes cell proliferation in prostate cancer. Int J Biol Macromol. 2019;122:1235-43.

56. Dai $Y$, Li D, Chen $X$, Tan X, Gu J, Chen M, Zhang X. Circular rna myosin light chain kinase (mylk) promotes prostate cancer progression through modulating mir-29a expression. Med Sci Monitor. 2018;24:3462.

57. Yao J-T, Zhao S-H, Liu Q-P, Lv M-Q, Zhou D-X, Liao Z-J, Nan K-J. Overexpression of CircRNA 100876 in non-small cell lung cancer and its prognostic value. Pathology - Research and Practice. 2017;213(5):453-6.

58. Hang D, Zhou J, Qin N, Zhou W, Ma H, Jin G, Hu Z, Dai J, Shen H. A novel plasma circular RNA circ FARSA is a potential biomarker for non-small cell lung cancer. Cancer Med. 2018;7(6):2783-91.

59. Wang L, Liu S, Mao Y, Xu J, Yang S, Shen H, Xu W, Fan W, Wang J. CircRNF13 regulates the invasion and metastasis in lung adenocarcinoma by targeting miR-93-5p. Gene. 2018;671:170-7.

60. Song Y-Z, Li J-F. Circular RNA hsa_circ_0001564 regulates osteosarcoma proliferation and apoptosis by acting miRNA sponge. Biochem Biophys Res Commun. 2018;495(3):2369-75.
61. Jin $\mathrm{H}$, Jin $\mathrm{X}$, Zhang $\mathrm{H}$, Wang W. Circular RNA hsa-circ-0016347 promotes proliferation, invasion and metastasis of osteosarcoma cells. Oncotarget. 2017;8(15):25571.

62. Zhang H, Wang G, Ding C, Liu P, Wang R, Ding W, Tong D, Wu D, Li C, Wei Q. Increased circular RNA UBAP2 acts as a sponge of miR-143 to promote osteosarcoma progression. Oncotarget. 2017;8(37):61687.

63. Li F, Zhang L, Li W, Deng J, Zheng J, An M, Lu J, Zhou Y. Circular RNA ITCH has inhibitory effect on ESCC by suppressing the Wnt/ $\beta$-catenin pathway. Oncotarget. 2015;6(8):6001.

64. Dou Y, Cha DJ, Franklin JL, Higginbotham JN, Jeppesen DK, Weaver AM, Prasad N, Levy S, Coffey RJ, Patton JG. Circular RNAs are down-regulated in KRAS mutant colon cancer cells and can be transferred to exosomes. Sci Rep. 2016:6:37982.

65. Chen J, Li Y, Zheng Q, Bao C, He J, Chen B, Lyu D, Zheng B, Xu Y, Long Z. Circular RNA profile identifies circPVT1 as a proliferative factor and prognostic marker in gastric cancer. Cancer Lett. 2017;388:208-19.

66. Yang P, Qiu Z, Jiang Y, Dong L, Yang W, Gu C, Li G, Zhu Y. Silencing of cZNF292 circular RNA suppresses human glioma tube formation via the Wnt/B-catenin signaling pathway. Oncotarget. 2016;7(39):63449.

67. Xu L, Zhang M, Zheng X, Yi P, Lan C, Xu M. The circular RNA ciRS-7 (Cdrlas) acts as a risk factor of hepatic microvascular invasion in hepatocellular carcinoma. J Cancer Res Clin Oncol. 2017;143(1):17-27.

68. Tang X, Wang J, Xia X, Tian J, Rui K, Xu H, Wang S. Elevated expression of ciRS-7 in peripheral blood mononuclear cells from rheumatoid arthritis patients. Diagn Pathol. 2019;14(1):11.

69. Pan H, Li T, Jiang Y, Pan C, Ding Y, Huang Z, Yu H, Kong D. Overexpression of circular RNA ciRS-7 abrogates the tumor suppressive effect of miR-7 on gastric cancer via PTEN/PI3K/AKT signaling pathway. J Cell Biochem. 2018; 119(1):440-6.

70. Hu M, Zhu S, Xiong S, Xue X, Zhou X. MicroRNAs and the PTEN/PI3K/Akt pathway in gastric cancer. Oncol Rep. 2019;41(3):1439-54.

71. Hammond E, Khurana A, Shridhar V, Dredge K. The role of heparanase and sulfatases in the modification of heparan sulfate proteoglycans within the tumor microenvironment and opportunities for novel cancer therapeutics. Front Oncol. 2014;4:195.

72. Zhang G, Zhang G. Upregulation of FoxP4 in HCC promotes migration and invasion through regulation of EMT. Oncol Lett. 2019;17(4):3944-51.

73. Wang F, Zu Y, Huang W, Chen H, Xie H, Yang Y. LncRNA CALML3-AS1 promotes tumorigenesis of bladder cancer via regulating ZBTB2 by suppression of microRNA-4316. Biochem Biophys Res Commun. 2018;504(1):171-6.

74. Wang B, Hsu S-H, Majumder S, Kutay H, Huang W, Jacob ST, Ghoshal K. TGF $\beta$-mediated upregulation of hepatic miR-181b promotes hepatocarcinogenesis by targeting TIMP3. Oncogene. 2010;29(12):1787.

75. Huang JF, Guo YJ, Zhao CX, Yuan SX, Wang Y, Tang GN, Zhou WP, Sun SH. Hepatitis $B$ virus $X$ protein ( $H B X)$-related long noncoding RNA (IncRNA) down-regulated expression by HBx (Dreh) inhibits hepatocellular carcinoma metastasis by targeting the intermediate filament protein vimentin. Hepatology. 2013:57(5):1882-92.

76. Liu K-S, Pan F, Mao X-D, Liu C, Chen Y-J: Biological functions of circular RNAs and their roles in occurrence of reproduction and gynecological diseases. Am J Transl Res 2019, 11(1):1.

77. Torre LA, Trabert B, DeSantis CE, Miller KD, Samimi G, Runowicz CD, Gaudet MM, Jemal A, Siegel RL. Ovarian cancer statistics, 2018. CA Cancer J Clin. 2018;68(4):284-96

78. Meng S, Zhou H, Feng Z, Xu Z, Tang Y, Li P, Wu M. CircRNA: functions and properties of a novel potential biomarker for cancer. Mol Cancer. 2017;16(1):94.

79. Guo Q, He Y, Sun L, Kong C, Cheng Y, Zhang G. In silico detection of potential prognostic circRNAs through a re-annotation strategy in ovarian cancer. Oncol Lett. 2019;17(4):3677-86.

80. Hu J, Wang L, Chen J, Gao H, Zhao W, Huang Y, Jiang T, Zhou J, Chen Y. The circular RNA circ-ITCH suppresses ovarian carcinoma progression through targeting miR-145/RASA1 signaling. Biochem Biophys Res Commun. 2018;505(1):222-8.

81. Xu X, Jia S-Z, Dai Y, Zhang J-J, Li X, Shi J, Leng J, Lang J. The relationship of circular RNAs with ovarian endometriosis. Reprod Sci. 2018;25(8):1292-300.

82. Bao L, Zhong J, Pang L. Upregulation of circular RNA VPS13C-has-circ001567 promotes ovarian Cancer cell proliferation and invasion. Cancer Biother Radiopharm. 2018.

83. Xie J, Wang S, Li G, Zhao X, Jiang F, Liu J, Tan W. circEPSTI1 regulates ovarian cancer progression via decoying miR-942. J Cell Mol Med. 2019; 23(5):3597-602. 
84. Li QH, Liu Y, Chen S, Zong ZH, Du YP, Sheng XJ, Zhao Y. circ-CSPP1 promotes proliferation, invasion and migration of ovarian cancer cells by acting as a miR-1236-3p sponge. Biomed Pharmacother. 2019;114:108832.

85. Liu N, Zhang J, Zhang L, Wang L. CircHIPK3 is upregulated and predicts a poor prognosis in epithelial ovarian cancer. Eur Rev Med Pharmacol Sci. 2018;22(12):3713-8.

86. Teng F, Xu J, Zhang M, Liu S, Gu Y, Zhang M, Wang X, Ni J, Qian B, Shen R. Comprehensive circular RNA expression profiles and the tumor-suppressive function of circHIPK3 in ovarian cancer. Int J Biochem Cell Biol. 2019;1 12:8-17.

87. Gao Y, Zhang C, Liu Y, Wang M. Circular RNA profiling reveals circRNA1656 as a novel biomarker in high grade serous ovarian cancer. Bioscience trends. 2019;13(2):204-11.

88. Zhang M, Xia B, Xu Y, Zhang Y, Xu J, Lou G. Circular RNA (hsa_circ 0051240) promotes cell proliferation, migration and invasion in ovarian cancer through miR-637/KLK4 axis. Artificial Cells Nanomed Biotechnol. 2019:47(1):1224-33.

89. Luo L, Gao Y, Sun X. Circular RNA ITCH suppresses proliferation and promotes apoptosis in human epithelial ovarian cancer cells by sponging miR-10a-a. Eur Rev Med Pharmacol Sci. 2018;22(23):8119-26.

90. Zou T, Wang P, Gao Y, Liang W. Circular RNA_LARP4 is lower expressed and serves as a potential biomarker of ovarian cancer prognosis. Eur Rev Med Pharmacol Sci. 2018;22(21):7178-82.

91. Ning L, Long B, Zhang W, Yu M, Wang S, Cao D, Yang J, Shen K, Huang Y, Lang J. Circular RNA profiling reveals circEXOC6B and circN4BP2L2 as novel prognostic biomarkers in epithelial ovarian cancer. Int J Oncol. 2018;53(6): 2637-46.

92. Jeck WR, Sharpless NE. Detecting and characterizing circular RNAs. Nat Biotechnol. 2014;32(5):453.

93. Ahmed I, Karedath T, Andrews SS, Al IK, Mohamoud YA, Querleu D, Rafii A, Malek JA. Altered expression pattern of circular RNAs in primary and metastatic sites of epithelial ovarian carcinoma. Oncotarget. 2016;7(24):36366.

94. Lee YS, Dutta A. The tumor suppressor microRNA let-7 represses the HMGA2 oncogene. Genes Dev. 2007;21(9):1025-30.

95. Mishra PJ, Song B, Mishra PJ, Wang Y, Humeniuk R, Banerjee D, Merlino G, Ju J, Bertino JR. MiR-24 tumor suppressor activity is regulated independent of p53 and through a target site polymorphism. PLoS One. 2009:4(12):e8445.

96. Adélaïde J, Finetti P, Bekhouche I, Repellini L, Geneix J, Sircoulomb F, Charafe-Jauffret E, Cervera N, Desplans J, Parzy D. Integrated profiling of basal and luminal breast cancers. Cancer Res. 2007;67(24):11565-75.

97. Patzke S, Hauge H, Sioud M, Finne EF, Sivertsen EA, Delabie J, Stokke T, Aasheim $\mathrm{H}$-C. Identification of a novel centrosome/microtubule-associated coiled-coil protein involved in cell-cycle progression and spindle organization. Oncogene. 2005;24(7):1159.

98. Wang Y, Yan S, Liu X, Zhang W, Li Y, Dong R, Zhang Q, Yang Q, Yuan C, Shen K. miR-1236-3p represses the cell migration and invasion abilities by targeting ZEB1 in high-grade serous ovarian carcinoma. Oncol Rep. 2014; 31(4):1905-10

99. Chen B, Wei W, Huang X, Xie X, Kong Y, Dai D, Yang L, Wang J, Tang H, Xie $X$. circEPSTI1 as a prognostic marker and mediator of triple-negative breast cancer progression. Theranostics. 2018;8(14):4003.

100. Chen D, Lu X, Yang F, Xing N. Circular RNA circHIPK3 promotes cell proliferation and invasion of prostate cancer by sponging miR-193a-3p and regulating MCL1 expression. Cancer Manag Res. 2019;11:1415.

101. Yu H, Chen Y, Jiang P. Circular RNA HIPK3 exerts oncogenic properties through suppression of miR-124 in lung cancer. Biochem Biophys Res Commun. 2018:506(3):455-62.

102. Zheng Q, Bao C, Guo W, Li S, Chen J, Chen B, Luo Y, Lyu D, Li Y, Shi G. Circular RNA profiling reveals an abundant circHIPK3 that regulates cell growth by sponging multiple miRNAs. Nat Commun. 2016;7:11215.

103. Obiezu CV, Scorilas A, Katsaros D, Massobrio M, Yousef GM, Fracchioli S, de la Longrais IAR, Arisio R, Diamandis EP. Higher human kallikrein gene 4 (KLK4) expression indicates poor prognosis of ovarian cancer patients. Clin Cancer Res. 2001;7(8):2380-6.

104. Taylor DD, Gercel-Taylor C. MicroRNA signatures of tumor-derived exosomes as diagnostic biomarkers of ovarian cancer. Gynecol Oncol. 2008;1 10(1):13-21.

105. Sorrentino A, Liu C-G, Addario A, Peschle C, Scambia G, Ferlini C. Role of microRNAs in drug-resistant ovarian cancer cells. Gynecol Oncol. 2008; 111(3):478-86

\section{Publisher's Note}

Springer Nature remains neutral with regard to jurisdictional claims in published maps and institutional affiliations.

Ready to submit your research? Choose BMC and benefit from:

- fast, convenient online submission

- thorough peer review by experienced researchers in your field

- rapid publication on acceptance

- support for research data, including large and complex data types

- gold Open Access which fosters wider collaboration and increased citations

- maximum visibility for your research: over $100 \mathrm{M}$ website views per year

At $\mathrm{BMC}$, research is always in progress.

Learn more biomedcentral.com/submissions 